\title{
Un análisis histórico de los mecanismos no penales centroamericanos para Colombia
}

William Eugene Ulrich*

Magíster en Derecho Administrativo, Universidad del Cauca. Profesorinvestigador, Universidad Cooperativa de Colombia, sede Popayán. Correo electrónico:

william.ulricha@campusucc.edu.co

Recibido: 14 de febrero del 2017 Aprobado: 22 de abril del 2017

Cómo citar este artículo: William Eugene Ulrich. Un análisis histórico de los mecanismos no penales centroamericanos para Colombia. DIxI 26. Mayo 2017. Pág. 57. doi: http://dx.doi.org/10.16925/ di.v19i26.1951

\section{Resumen}

Propósito: el presente artículo propone un acercamiento histórico-comparativo de la historia, el desarrollo y las formas de solución implementadas en los conflictos internos que vivieron en las décadas de los ochenta y noventa Guatemala, El Salvador y Nicaragua, y un contraste con la actual finalización de conflicto que vive Colombia con las FARc. Descripción: la naturaleza de irregularidad de los conflictos centroamericanos y su inmensa similitud con el conflicto colombiano - el cual, al igual que aquellos, se enfrentó a una guerrilla organizada-, es un punto fuerte que autoriza el desarrollo de un análisis que permita observar de manera critica los eventos históricos, y traerlos a un presente en el que lo vivido suele repetirse de forma casi inevitable. Punto de vista: los conflictos centroamericanos ofrecen un inmejorable espacio de análisis para el actual trabajo, ya que su impresionante semejanza con el conflicto colombiano provee de una inmensa cantidad de material que debe ser tenido en cuenta y ofrece un gran número de propuestas que no pueden ignorarse. Conclusiones: se hace necesario exponer los diferentes casos y experiencias para extraer los aprendizajes necesarios y no repetir los errores cometidos en el pasado.

Palabras clave: amnistías, Centroamérica, Colombia, indultos, posconflicto. 


\title{
A Historical Analysis of the Central American Non-criminal Mechanisms for Colombia
}

\begin{abstract}
Purpose: This article proposes a historical-comparative approach to the history, development and forms of solutions implemented by Guatemala, El Salvador and Nicaragua in the internal conflicts they experienced in the eighties and nineties, and a comparison is made with the end of the conflict between Colombia and FARC. Description: The irregular nature of Central American conflicts and their immense similarity with the conflict in Colombia-which, like them, faced an organized guerrilla-allow for an analysis to observe historical events critically and bring them to a present in which experiences are repeated almost inevitably. Point of view: Central American conflicts offer an excellent opportunity for analysis for the current work since their striking resemblance to the Colombian conflict provides a considerable amount of material that must be taken into consideration and many proposals that cannot be ignored. Conclusions: It is necessary to present various cases and experiences to extract the necessary learning and not repeat the mistakes made in the past.
\end{abstract}

Keywords: amnesties, Central America, Colombia, pardons, post-conflict.

\section{Uma análise histórica dos mecanismos não penais centro-americanos para a Colômbia}

\section{Resumo}

Propósito: este artigo propõe uma aproximação histórico-comparativa da história, do desenvolvimento e das formas de solução implantadas nos conflitos internos que a Guatemala, El Salvador e a Nicarágua viveram na década de oitenta e noventa, e um contraste com a atual finalização do conflito que a Colômbia vive com as Forças Armadas Revolucionárias da Colômbia - Exército do Povo (Farc). Descrição: a natureza de irregularidade dos conflitos centro-americanos e sua imensa semelhança com o conflito colombiano - o qual, assim como aqueles, enfrentou uma guerrilha organizada - é um ponto forte que autoriza o desenvolvimento de uma análise que permite observar de maneira crítica os eventos históricos e trazê-los a um presente no qual o vivido costuma repetir-se de forma quase inevitável. Ponto de vista: os conflitos centro-americanos oferecem um imemorável espaço de análise para o atual trabalho, já que sua impressionante semelhança com o conflito colombiano provê de uma imensa quantidade de material que deve ser considerado e oferece um grande número de propostas que não podem ser ignoradas. Conclusões: faz-se imprescindível expor os diferentes casos e experiências para extrair as aprendizagens necessárias e não repetir os erros do passado.

Palavras-chave: anistias, Colômbia, El Salvador, Guatemala, indultos, Nicarágua, pós-conflito. 


\section{INTRODUCCIÓN}

El objetivo del presente trabajo es el análisis de los mecanismos no penales (entre otros, las amnistías, el perdón y olvido, etc.) a aplicar en el posconflicto colombiano, desde una perspectiva histórico-comparativa, esto es, un acercamiento a las posibilidades que ofrecen para Colombia los diferentes mecanismos no penales por medio del análisis de los hechos ocurridos en Centroamérica.

La posibilidad de finalizar un dilatado conflicto es una perspectiva que, sin lugar a dudas, propone la necesidad de cambios, tanto económicos, como sociales, y por supuesto de tipo legal, pero aun a pesar de estos cambios que necesariamente deben hacerse, es de vital importancia no descuidar el flanco del pasado y de las experiencias vividas. Es pertinente mirar hacia atrás, donde residen grandes cúmulos de conocimiento que pueden dar luces de "qué hacer y qué no hacer" en este proyecto de paz, consideraciones que resultan de increíble utilidad y que, de ignorarse, pueden significar un traspié y una recaída en las hostilidades.

La asimetría del conflicto de Colombia se asemeja a lo ocurrido en Centroamérica y propone un acercamiento a lo que el posconflicto puede ofrecer en cuanto a mecanismos no penales. Por tanto, es necesario hacer la aclaración, ya que la situación jurídica de Centroamérica dista mucho de la actual en cuanto a organismos y leyes de tipo internacional que deben ser obedecidas por los Estados, en lo atinente al manejo de delitos. ${ }^{1}$ Esto puede ofrecer una variación en el manejo de los posibles mecanismos no penales, claro está que los delitos de lesa humanidad que define el mencionado estatuto tendrán que ser investigados y juzgados por la Corte Penal Internacional (CPI).

Colombia es un ejemplo muy especial con respecto a otros países que han vivido violencia relacionada con grupos armados al margen de la ley e ideologías similares, ya que la democracia colombiana - arguyen - es la más firme de América Latina, lo cual, por supuesto, es motivo de discusión. ${ }^{2}$ Esto

\footnotetext{
1. El estatuto de Roma, vigente desde 1998, crea la Corte Penal Internacional (CPI), de manera que no estaba vigente para la época de paz en Centroamérica, lo cual propone una gran diferencia con Centroamérica y el eventual posconflicto de Colombia.

2. A pesar de que exista una democracia duradera en Colombia, tal y como lo afirma el portal Colombia.co, existen otros medios que atacan este punto de vista y catalogan a Colombia como una democracia imperfecta, dentro de un rango de cuatro posibilidades: "democracias plenas", "democracias imperfectas", aquellos que tienen modelos "híbridos" y los "regímenes autoritarios". $C f$. Colombia.co. ¿Por qué se dice que Colombia tiene la democracia
}

en contraste con las democracias centroamericanas, las cuales antes de la paz vivieron largos periodos de dictadura, como el caso de Nicaragua con la familia Somoza, y de Guatemala con sus diferentes líderes militares después de la guerra civil que asoló al país. ${ }^{3}$ Asimismo, El Salvador, donde después de un prolongado e inevitable conflicto, de acuerdo con Martín-Baró, ${ }^{4}$ este terminó con negociaciones entre el FMLN y el Gobierno de El Salvador, en el castillo de Chapultepec, México, en 1992.

Si bien las aparentes diferencias estructurales que ofrecen los conflictos vividos en Centroamérica proponen situaciones que distan de las de Colombia (en cuanto a lo que se refiere al conflicto), lo cierto es que los mecanismos utilizados por los gobiernos en sus negociaciones de salida a estas "guerras" pueden ofrecer una visión del posconflicto y los retos que esto le supondrá al país, tanto en la dimensión cultural y económica, como, por supuesto, legal, la cual será el enfoque de este trabajo, con una orientación hacia la aplicación de mecanismos que no supondrán cárcel para los perpetradores de los delitos que en el desarrollo de este conflicto se han dado.

Se busca analizar y estudiar diferentes experiencias de mecanismos de justicia transicional implementados en conflictos de algunos países de Centroamérica, los cuales en el siglo pasado aplicaron penas alternativas de tipo penal y no penal como una salida a conflictos internos de similares características al colombiano. Esto con el fin de proponer mediante un estudio de justicia, con un enfoque histórico, una visión alternativa para el posconflicto colombiano.

Con la esperanza de todo el país en un posible fin del conflicto a la vista, han surgido imperiosamente preguntas que inquietan a los colombianos, quienes al tiempo que claman justicia efectiva para los criminales con ocasión del conflicto interno, anhelan de una vez por todas su final: ¿qué tipo de justicia deberá aplicarse a los victimarios y extenderse a

más antigua de América Latina? Colombia.co. Disponible en http://www.colombia.co/esta-es-colombia/historia/por-que-se-dice-que-colombia-tiene-la-democracia-mas-antigua-de-americalatina/; y Constanza Hola Chamy. ¿Qué países de América Latina son los más y los menos democráticos? ввс.сом. Enero 20 del 2015. Disponible en http://www.bbc.com/mundo/ noticias/2015/ 01/150119_democracia_indice_economist_latinoamerica_ch.

3. Véase El País. El asesinato de Anaya pone en peligro el plan de paz en El Salvador. El País.com. Octubre 28 de 1987. Disponible en http://elpais.com/diario/1987/10/ 28/internacional/562374016_850215.html

4. Véase Ignacio Martín-Baro. La GUERRA CIVIL EN EL SALVAdor. Universidad Centroamericana José Simeón Cañas. (1981). Disponible en http:// www.uca.edu.sv/coleccion-digital-IMB/ articulo/la-guerra-civil-en-el-salvador/ 
las numerosas víctimas del conflicto colombiano? ¿Hasta dónde será posible llevar ante la justicia a todos aquellos que cometieron delitos durante este conflicto? ¿En qué medida y con qué medios será capaz la justicia colombiana de procesar de forma ágil y certera a los perpetradores? ¿Perdonará en pleno la sociedad colombiana a aquellos que durante años han cometido delitos atroces en nombre de la igualdad y de la defensa del Estado en este territorio? Todas preguntas que deben abordarse sin hesitación alguna, por medio de diferentes mecanismos que aseguren que todos los daños y sufrimientos causados tengan un acercamiento a la justicia con un resultado de una verdad procesal, la cual conlleve a una verdad material e histórica de los acontecimientos de esta guerra crónica.

Los mecanismos de justicia no penal evidencian el deseo de un sector que entiende las carencias de un sistema judicial que podría llegar al punto del colapso, dada la falta de operadores jurídicos para enfrentar los diferentes casos que propone un escenario de posconflicto.

Desde el punto de vista académico, este tema ofrece una inmejorable posición para explicar con ejemplos históricos de otros procesos vividos cómo puede funcionar un proceso de dejación de las armas y los efectos que esto tendría en la sociedad colombiana. Esto es, ¿cómo se puede traer de nuevo a la sociedad a aquellos que en el pasado fueron combatientes, y darles la oportunidad de dejar las armas de forma concertada al ofrecerles beneficios necesarios para que la transición sea lo menos traumática, tanto para la sociedad civil, como para aquellos que tras un proceso de decenios se han apartado de la sociedad a fin de combatir la institucionalidad colombiana? Claro está, sin dejar de lado las experiencias de aprendizaje que traen casos similares en Centroamérica, sin ser estas una imposición histórica para el caso nacional.

\section{EL POSCONFLICTO Y LOS MECANISMOS NO PENALES EN NiCARAgUA}

El conflicto en Nicaragua tiene un tinte especial que obligatoriamente debe considerarse, ya que este lo diferencia de los demás. En 1979, el Frente Sandinista de Liberación Nacional (FSLN) llegó al poder tras un ataque sorpresivo que dio por terminada la dictadura de la familia Somoza e instauró en este país un gobierno de corte comunista al estilo cubano, con una economía mixta altamente planificada y pluralismo político, lo que finalmente no ocurrió, tal y como lo explican Matul y Ramírez. ${ }^{5}$

A partir de la toma del poder de este grupo, ocurre una curiosa inversión de papeles que poco se ha visto, esto es, los grupos "guerrilleros", bien pertenecieran a ideologías consideradas de naturaleza "capitalista", o bien de "derecha" y que, patrocinadas por el Gobierno de los Estados Unidos, en un claro tinte ideológico contrario al propiciado por Cuba y la Unión de Repúblicas Socialistas Soviéticas (URRS), no estaban dispuestos a permitir la proliferación del comunismo en América. ${ }^{6}$

El desgaste de la guerra entre el Estado de Nicaragua y la Contra llevó a que las partes decidieran poner fin al conflicto, lo cual tuvo, al igual que para el resto de países de Centroamérica en conflicto, un inicio por medio del acuerdo de Esquipulas (o Esquipulas I), en 1986. Mediante este acuerdo, se establecía la voluntad de cinco mandatarios de la región ${ }^{7}$ de lograr una paz "firme y duradera".

El segundo acuerdo de Esquipulas no demoró y, en 1987, los mismos cinco firmantes del anterior acuerdo llegaron a un acuerdo más fuerte y vinculante para el logro de la paz en la región. Este contemplaba cuestiones más de fondo, y luego de su preámbulo empieza con el "procedimiento para establecer la paz firme y duradera para Centroamérica”, seguido de su primer numeral que establece el "diálogo". Este puso de presente y reconoció las profundas divisiones que habían causado las hostilidades, lo cual debía ser reparado mediante la reconciliación nacional, tendiente a la inclusión de los grupos opositores a este nuevo orden. En adición a este acuerdo de Esquipulas de 1987, mediante decreto presidencial, se creó la Comisión Nacional de Reconciliación, órgano que, de acuerdo con lo pactado en Esquipulas, sería el encargado de:

5. Véase Daniel Matul y Alonso Ramírez. El proceso de paz en Centroamérica. Agendas pendientes y nuevos focos de conflictividad: Los casos de Guatemala y Nicaragua. Pensamiento Propio 29. Págs. 91-124. Disponible en http://www.cries.org/29.pdf

6. Cf. Camilo Devia-Garzón, Dina Ortega y Marcela Magallanes. (2014). Violencia LUEGo DE LA PAZ: ESCENARIOS DE POSCONflicto en Centroamérica. Universidad Militar Nueva Granada. Disponible en http://revista.urepublicana.edu.co/wp-content/ uploads/2015/02/Violencia-luego-de-la-paz-escenarios-deposconflicto-en-Centro-.pdf

7. Oscar Arias-Sánchez, presidente de Costa Rica; Marco Vinicio Cerezo-Arévalo, presidente de Guatemala; José Napoleón Duarte, presidente de El Salvador; José Azcona-Hoyo, presidente de Honduras; y Daniel Ortega-Saavedra, presidente de Nicaragua. 
Verificación del cumplimiento de los compromisos que los cinco Gobiernos centroamericanos contraen con la firma del presente documento, en materia de amnistía, cese del fuego, democratización y elecciones libres, se creará una Comisión Nacional de Reconciliación que tendrá las funciones de constatar la vigencia real del proceso de reconciliación nacional, así como el respeto irrestricto de todos los derechos civiles y políticos de los ciudadanos centroamericanos. ${ }^{8}$

Se propone, dentro de este numeral, el ítem de amnistía, el cual es fundamental, ya que constituye la aplicación de un mecanismo no punitivo, una medida que busca manejar el escenario de posconflicto sin tener que acceder a tribunales que castigarán los delitos de los numerosos perpetradores que tienen estos dilatados conflictos. Esta amnistía busca, prima facie, la expedición de decretos para tal fin, y que a partir de la expedición de ellos las fuerzas irregulares liberen a quienes estén retenidos bajo su poder.

Dicho acuerdo exhorta a un cese de hostilidades en los territorios, con el compromiso de los Estados firmantes de utilizar los medios constitucionales en su poder para el logro de dicho objetivo, situación que efectivamente se logró en Nicaragua entre el FSLN y la Resistencia o Contras.

El Ejecutivo Nicaragüense elaboró y aplicó amnistías para aquellos que participaron de las hostilidades desde 1979 hasta 1990, fecha de finalización de estas. Mediante la Ley N. ${ }^{\circ} 81$ del 13 de Marzo de 1990 se extendió una amnistía amplia e incondicional por delitos políticos y comunes conexos, lo cual abrió una brecha grande de posibilidades a fin de lograr dicho beneficio; adicional a la amnistía, todos aquellos que estuvieren privados de su libertad por hechos relacionados al conflicto debían ser liberados.

Vale la pena destacar que esta primera amnistía concedida se da como gesto de buena voluntad con el proceso de paz, tal y como se enuncia en la parte motiva de la ley: "Que el Diálogo Nacional, que estamos pronto a iniciar, se vería grandemente fortalecido con una amnistía amplia e incondicional de los nicaragüenses involucrados en tales hechos"; 9 lo cual, sin ser pretensioso, resulta una buena estrategia para mejorar las condiciones de negociación con un grupo como la Contra Nicaragüense. Además de los

\footnotetext{
8. Véase Acuerdo de Esquipulas, I. I. Procedimiento para ESTABlecer la PAZ Firme y DURAdera en Centroamérica. Ciudad de Guatemala. (1987). Pág. 7.

9. Véase Ley N.o 81 de 13 de marzo de 1990 [Asamblea Nacional de la República de Nicaragua]. Gaceta N.o 53 de 15 de marzo de 1990
}

beneficios anteriores, también se hace una concesión especial a los servidores y empleados públicos que hayan cometido delitos descritos en el Libro Segundo, Título viı del Código Penal y sus Reformas, en particular la Ley N. 217 del 12 de Noviembre de $1985 .^{10}$

En 1990, hubo elecciones y se incluyó a la Unión Nacional Opositora (UNO), con su candidata Violeta Chamorro, quien derrotó al FSLN con un $54 \%$ de los votos, frente a un $41 \%$ de Daniel Ortega del FsLN. ${ }^{11}$ Luego de las elecciones, se suscribió el acuerdo de Toncontín, en el cual, efectivamente, la resistencia nicaragüense aceptaba los resultados de las elecciones realizadas y se comprometía a desmovilizar a sus filas con el compromiso de ayudas de tipo humanitario para sus desmovilizados.

Es importante destacar que este proceso de desmovilización ocurrió con un proceso democrático posterior a un conflicto de 11 años, el cual, de manera definitiva, incluyó, dentro del ámbito político nacional, a un actor armado que hasta poco antes había hecho una oposición armada y violenta. Vale la pena destacar que la posición de los grupos militares fue un factor decisivo a la hora de terminar el conflicto, ya que ellos fueron partidarios de una salida negociada. $^{12}$

Existe una segunda ley de amnistía promulgada por la recién electa presidenta de la República, el Decreto-Ley N. ${ }^{\circ}$ 47-91, en el cual, en las mismas condiciones de la primera ley dictada, se concede una amplia e incondicional amnistía por todos los delitos, pero por un lapso mucho más reducido al anterior (que abarcó las épocas más crudas del conflicto). Esta norma cubrió el periodo comprendido entre el 10 de mayo de 1990 hasta la fecha de su publicación, que se dio el 30 de diciembre de 1991 . $^{13}$

La política de desmovilización, a partir de un suceso democrático, es fundamental en el proceso de paz de Nicaragua, ya que esto garantizó que aquellos que se oponían se incluyeran de nuevo en la vida civil, pero con una situación algo preocupante sobre

10. Dicha norma versa sobre los delitos contra la administración pública y delitos contra la administración de justicia. Véase http:// www.poderjudicial.gob.ni/arc-pdf/spley419.pdf

11. Véase Miguel Ángel Bastenier. Violeta Chamorro: "Aqui mando yo". El PAís.com. Marzo 11 de 1990). Disponible http:// elpais.com/diario/1990/03/11/internacional/63711 0005_850215. html el 19 de septiembre de 2015

12 Véase V. García-Pinzón. Reformas al sector seguridad en contextos de post-conflicto armado: experiencias en Centroamérica y consideraciones sobre el caso colombiano. Ponencia presentada en Conferencia Flacso-ISA: "Poderes regionales y globales en un MUNDO CAMBIANTE", Buenos Aires, 2014.

13 Véase Decreto-Ley N. ${ }^{\circ}$ 47-91 [Presidencia de la República de Nicaragua]. Gaceta N. ${ }^{\circ} 246$ de 1991. 
los hechos, esto es, nunca se creó una comisión de la verdad que visibilizara las razones por las cuales habían ocurrido el conflicto, las muertes, las torturas y las violaciones a los derechos humanos y al derecho internacional humanitario (DIH), con el fin de evitar su repetición. Esto deja un sinsabor frente a lo ocurrido, ya que las reinserciones y amnistías que propuso Esquipulas II se ejecutaron sin dejar responsables frente a la comunidad y a los ojos de la comunidad internacional.

De manera curiosa también, debe aclararse que las fuerzas militares no tuvieron una purga ni un cambio, y pasaron de ser una fuerza militar financiada y apoyada por la ideología comunista, a ser parte de un gobierno de derecha o conservador en manos de la resistencia nicaragüense. Ahora bien, esto tuvo su viraje a partir del cambio de mando en el Ejecutivo, por el cual se redujo el tamaño de los efectivos mediante licenciamientos de unos 87000 efectivos, a unos 12100 en la actualidad. ${ }^{14}$

Así, los cambios para el posconflicto nicaragüense son visibles. De acuerdo con lo pactado en Esquipulas I y II, hubo amnistías, desmovilizaciones y reinserción de los miembros de la Resistencia a la vida civil, lo que finalizó de tajo el conflicto de algo más de una década, con la salvedad de una comisión de la verdad que permitiera dejar sentado un precedente de no repetición para el futuro de Nicaragua.

En la actualidad, Nicaragua ha superado el conflicto interno que vivió. La democracia se reestableció de manera tal que, en el 2006 y 2011, Daniel Ortega, líder del FSLN, estuvo en el poder de manera indiscutida, después de años de dirigencia de partidos de otras corrientes.

Resulta entonces necesario realizar un balance sobre lo ocurrido en este conflicto. Es evidente que el punto de partida fue la inconformidad y las graves necesidades padecidas por el pueblo nicaragüense. Tras la prolongadísima estancia en el poder de la familia Somoza (1934-1979), crearon un hábitat perfecto para la formación de pensamientos opuestos al régimen, aunado a la proliferación de pensamientos considerados de "izquierda", patrocinados por la Revolución cubana, la cual, finalmente, se alza como el bastión del comunismo en América.

La concentración de la riqueza de un país en pocas manos siempre ha sido un detonante para las guerras civiles, y en este caso no fue la excepción, tal y como lo afirmó Lord Acton: "El poder corrompe

14. Véase Ejército, D. N. EJÉrcito de Nicaragua 30 AÑos DE VIDA INSTITUCIONAL:(1979-2009). Ejército de Nicaragua. (2009). y el poder absoluto corrompe absolutamente". La familia Somoza era, en efecto, el gran terrateniente de Nicaragua, pues llegó a tener una tercera parte de las tierras cultivables de Nicaragua, y una fortuna que ascendía a los 500 o 600 millones de dólares. ${ }^{15}$

Esta insostenible posición del pueblo llevo a la creación del FSLN, el cual sin titubeos terminó derrocando a Somoza e instauró su propio gobierno, tal como se mencionó antes. El conflicto, a partir de ese momento, es un laboratorio de ideologías y pugnas geopolíticas entre los Estados Unidos y la Unión Soviética, quienes finalmente terminarían patrocinando con ingentes cantidades de dinero y material bélico las luchas entre el Gobierno y la Contra.

A partir de la firma de los acuerdos de Esquipulas, es posible observar la luz al final del túnel, porque es, a partir de este momento, que empieza una ronda de charlas y negociaciones que darían fin a esa guerra y llevarían a una paz duradera.

Sin embargo, a efectos del análisis que se lleva a cabo del posconflicto nicaragüense, es necesario centrarse en los mecanismos no penales que se utilizaron y que están muy bien delimitados, pero que no pueden pasar sin un análisis más profundo. Así, entonces, se tiene que con la finalización del conflicto y la desmovilización de la Contra resultaría un hecho sin precedentes, como lo es la falta de creación de una comisión de la verdad. Esto ignoró los obvios beneficios que trae para la no repetición y la memoria histórica de un país conocer los orígenes, las razones, los hechos (a veces macabros) y, finalmente, a los responsables de lo ocurrido, en el propósito de cumplir con el imperativo de la no impunidad, el cual resulta tan necesario para estas situaciones. Se considera que esto fue una fórmula de escape a la responsabilidad de aquellos que cometieron crímenes de naturaleza atroz, quienes finalmente lograron evadir a la justicia.

Las normas que se crearon a fin de conceder amnistías amplias e incondicionales a los excombatientes, tanto de la Contra, como del Gobierno, terminaron por enterrar el tema de la responsabilidad con un regusto a impunidad que no es fácil apartar de la mente, ya que ninguno de los responsables de este dilatado y cruel conflicto tuvo las sanciones que merecía por sus crímenes.

15. Véase Historiaybiografias.com. La dictadura de los Somoza en Nicaragua Gobierno Autoritario de Somoza. Historiay bIografias. сом. 2016. Disponible en http://historiaybiografias.com/somoza/ 


\section{EL POSCONFLICTO Y LOS MECANISMOS NO PENALES EN El SALVAdor}

Las profundas diferencias en la repartición de la riqueza en El Salvador fueron un detonante para el conflicto que asoló al país durante la década de los ochenta, además de una dependencia política, económica y militar de la junta de gobierno. ${ }^{16}$ Debe considerarse el descomunal poder que adquirieron las fuerzas militares dentro de este país, tanto así que ninguna de las tres ramas del poder pudo poner freno a lo que estaba pasando. La creación de "escuadrones de la muerte" que funcionaban con la anuencia de autoridades militares, quienes muchas veces patrocinaron sus fechorías con la excusa de promulgar ideales políticos o cuestiones de beneficio personal, acrecentaron la crudeza de este conflicto. ${ }^{17}$

De acuerdo con Martín-Baró, ${ }^{18}$ el primer disparo de una guerra que duraría 12 años se dio el 10 de enero de 1981 a las cinco de la tarde, cuando un gran número de insurgentes del FMLN atacó diferentes puestos militares en una primera ofensiva a gran escala, resultado de dificultades a nivel de derechos fundamentales para la población, un gran número de decretos que restringían el derecho a la huelga, derechos sindicales y el reclutamiento de los funcionarios de instituciones de carácter público tales como la Administración Nacional de Acueductos y Alcantarillados (ANDA), la Administración Nacional de Telecomunicaciones (ANTEL), la Comisión Ejecutiva Hidroeléctrica del Río Lempa (CEL), y la Comisión Ejecutiva Portuaria Autónoma (CEPA). ${ }^{19}$

A partir de las elecciones del presidente José Napoleón Duarte, en 1984, empieza la misión de salir del conflicto, lo que lleva al país a la firma de los acuerdos de Esquipulas I y II, como propuesta de pacificación de Centroamérica, los cuales darían sus primeros resultados a partir del 4 de octubre de 1987, cuando el Gobierno y los representantes del FMLN se reunirían en la nunciatura apostólica salvadoreña con el fin de discutir una agenda para la negociación del fin del conflicto, situación mal vista por el gobierno del presidente Reagan en los Estados Unidos, claramente opuesto a negociar con grupos de naturaleza comunista. ${ }^{20}$ Debe también añadirse

16. Véase Ignacio Martín-Baro, supra, nota 4.

17. Véase Comisión de la Verdad para El Salvador. DE LA LOCURA

A LA ESPERANZA. Naciones Unidas. (1993).

18. Véase Ignacio Martín-Baro, supra, nota 4.

19. Id.

20. Véase El País, supra, nota 3. que la asamblea legislativa de El Salvador expidió el Decreto Ley 805, denominado "Ley de amnistía para el logro de la reconciliación nacional”, por el cual se ofrecían amnistías a todo tipo de delitos comunes y políticos, con la excepción de los autores de la muerte del arzobispo Oscar Arnulfo Romero, ${ }^{21}$ y otros delitos tales como secuestro y narcotráfico.

El primer momento de búsqueda de cese al fuego terminaría truncado por la muerte de Herbert Anaya-Sanabria, coordinador de una agencia no gubernamental de derechos humanos, a manos de pistoleros no identificados. A pesar de esto, se realizó una captura de un sospechoso que confesó haber participado en el homicidio para luego retractarse, no obstante, sería condenado por el homicidio en $1991 .^{22}$ Este episodio llevaría al FMLN a romper los diálogos con el gobierno de Duarte.

Solo se daría hasta dos años después el reinicio de las conversaciones en Venezuela, cuando se pactó "dirimir el conflicto por la vía pacífica". Posterior a esto, se firmó en Ginebra (Suiza) el acuerdo para discutir sobre temas tales como derechos humanos, reformas a la Constitución, además de la verificación de las Naciones Unidas; en San José de Costa Rica, se firmaría el mismo año el pacto que llevaría el nombre del mismo del lugar de su firma, y se creó la Misión de Observadores de las Naciones Unidas en El Salvador (onUsal); en Nueva York, se firmaría el acuerdo para la calendarización de los acuerdos de paz y la reducción de las fuerzas militares.

Con ocasión de la firma de los acuerdos de Chapultepec, la República de El Salvador y el Frente Farabundo Martí para la Liberación Nacional darían por terminado el conflicto que devastó durante un poco más de una década a este país. Dicho instrumento trajo consigo elementos muy interesantes que deben ser analizados para el objeto del presente estudio, y es el primero de ellos el régimen de las fuerzas militares que sufrieron una merma en las unidades creadas por las necesidades del conflicto, tales como los Batallones de Reacción Inmediata (BIRI), los cuales bajo el esquema de paz serían dados de baja, al igual que el número de oficiales del ejército, los cuerpos de reserva y de seguridad privada, así como las instalaciones utilizadas para el conflicto. Se implementó, además, un régimen de profesionalización que convertiría a las fuerzas armadas en una institución obediente, apolítica y no deliberante, lo cual

21. El Arzobispo Oscar Arnulfo Romero fue el arzobispo metropolitano de San Salvador, asesinado por disparos de francotirador mientras oficiaba misa.

22. Véase El País, supra, nota 3. 
la limpió de los sesgos políticos que con anterioridad habían ofrecido grandes dificultades.

En el numeral 5 de este primer capítulo, se señala también un poderoso, pero desgraciadamente inaplicable, acápite llamado "impunidad", el cual pondría en manos de la Comisión de la Verdad el trato de las violaciones de derechos humanos por parte de ambas partes mediante medidas "ejemplarizantes" que serían impartidas por las autoridades judiciales, lo cual en la práctica resultó ser no más que una promesa.

La imposibilidad señalada por la Comisión de la Verdad acerca del impedimento de llevar a juicio a los responsables por violaciones a los derechos humanos y otros resulta una gran decepción frente al proceso, ya que desconoce la norma antiimpunidad que con tanta fuerza defiende Ohlin. ${ }^{23}$ De acuerdo con esta, no solo es correcto que un Estado individualice y sancione a los responsables, sino que, además, resulta un imperativo moral hacerlo, porque de no procederse así, aquellos que salieron impunes estarían motivados a actuar de la misma forma, y aquellos que fueron víctimas no respetarían las normas a la hora de cometer una infracción.

La Comisión de la Verdad es un ente creado para contar la historia de los hechos y visibilizar las causas del conflicto. En el caso salvadoreño, narra los diferentes hechos ocurridos durante la docena de años de duración e investiga la ocurrencia de los mismos mediante las denuncias, citaciones y narraciones de los testigos de los diferentes eventos. Está en imposibilidad de juzgar; tan solo se limita a hacer recomendaciones al Estado con el fin de evitar la repetición de lo ocurrido. Dicha comisión emitió un documento titulado "De la locura a la esperanza", en el cual se lleva a cabo lo descrito arriba, y manifiesta la dificultad de llevar a la justicia a los perpetradores de los delitos ocurridos en razón a la misma debilidad del aparato judicial que estaba, en su mayoría, aún en manos de aquellos operadores que nunca llevaron a juicio a los responsables de los diferentes delitos cometidos durante las hostilidades.

El posconflicto para El Salvador trajo consigo una amnistía amplia por medio de dos leyes. Una de ellas es la Ley de Reconciliación Nacional de Enero de 1992, en la cual se reconoció que la firma del acuerdo de paz de Chapultepec debía fomentar un ambiente de perdón para El Salvador. El artículo 1 de dicha ley establece que se concede amnistía a todos aquellos

23. Véase Jens Ohlin. Justice After War. Cornell University. (2014). Disponible en http://papers.ssrn.com/sol3/papers.cfm? abstract_id=2531963 que hubieran cometido delitos en la modalidad de autoría mediata, inmediatos o de complicidad en delitos políticos, comunes y conexos, exceptuando el delito de secuestro y extorsión. La citada norma de la comisión legislativa también establece cómo aquellos que estén purgando penas deberán ser liberados y aquellos que fueren capturados o que estén siendo juzgados podrán proponer la extinción de la acción penal y solicitar el sobreseimiento. No está de más aclarar que dicha pieza legislativa habla sobre amnistía a delitos anteriores al primero de enero de 1992 y podrán acogerse también a los beneficios de la ley de reconciliación aquellos que se encuentren por fuera del país y los "lisiados" del FMLN en las mismas circunstancias.

La ley de amnistía general para la consolidación de la paz, por la cual se otorga este beneficio a todos aquellos que hubieren cometido delitos políticos o comunes, exceptuando los delitos de secuestro, extorsión y aquellos afines al narcotráfico, comparte similares características. Existe, y debe ser comentado, un acápite dentro de la ley que establece que la amnistía concedida extingue todo tipo de responsabilidad civil, lo cual es, a las luces de las obligaciones internacionales de un Estado como el salvadoreño, un exabrupto, ya que no puede ignorarse lo establecido en el Artículo 8 de la Convención Americana de Derechos Humanos: el deber de todos los Estados parte de garantizar el acceso a la justicia de sus ciudadanos; y en el Artículo 25 del mismo, que garantiza los recursos de amparo frente a la violación de los derechos de los ciudadanos.

No obstante la existencia de las leyes de amnistía mencionadas, no puede dejarse de lado que ellas resultan un obstáculo para la recta impartición de justicia por los hechos ocurridos en los que se violaron de forma masiva y sistemática los derechos de los ciudadanos, situaciones ampliamente documentadas y narradas en los documentos de la Comisión de la Verdad para El Salvador. El ejemplo más visible es el de la masacre del Mozote y de sus poblaciones vecinas. El BIRI Atlacatl, un grupo instruido por miembros del ejército de los Estados Unidos en técnicas de combate contrainsurgente, arribó en la población del Mozote el 10 de diciembre de 1981. Allí, llamó a la plaza pública a hombres, mujeres y niños, y les ordenó que permanecieran en sus hogares a riesgo de abrirse fuego contra aquellos que intentaran escapar. Temprano el día siguiente, 11 de diciembre, se hizo de nuevo la reunión de los pobladores en la plaza pública, donde fueron ejecutados primero los hombres, luego las mujeres y finalmente los niños. El saldo final fue 
de 143 individuos, de los cuales 131 eran menores de 12 años, cinco adolescentes y siete adultos; una de las víctimas era una mujer embarazada, tal y como lo constata la Comisión de la Verdad para El Salvador.

La Corte Interamericana de Derechos Humanos, en el 2012, revisó este caso en particular frente a las negativas del Estado salvadoreño de reabrirlo. En un fallo extenso dictaminó que las leyes de amnistía no podían ser un obstáculo para la impartición de justicia, pues esto crearía un ambiente de impunidad que no se acompasa con los compromisos de El Salvador, ya que no podrán ser cobijadas por leyes de amnistía aquellas personas que sean sospechosas o hayan sido juzgadas por crímenes de guerra. ${ }^{24}$ Esto sienta un precedente importante frente a la responsabilidad de un Estado por las amnistías concedidas, que si bien son un instrumento válido de acuerdo con lo establecido en el Artículo 6.5 del Protocolo II adicional a los Convenios de Ginebra de 1949, prevé que:

A la cesación de las hostilidades, las autoridades en el poder procurarán conceder la amnistía más amplia posible a las personas que hayan tomado parte en el conflicto armado o que se encuentren privadas de libertad, internadas o detenidas por motivos relacionados con el conflicto armado. ${ }^{25}$

Lo anterior no resulta como una obligación, o menos como una disposición de tipo definitivo, razón por la cual la legislación de El Salvador, frente a los delitos cometidos durante el conflicto, no puede ser un escudo que facilite la impunidad, aunque como ya se analizó, la realidad se opone a ello, ya que alega el Estado que los archivos que permitirían identificar a los que perpetraron esta masacre han sido extraviados.

El fallo de la Corte Interamericana mencionado sanciona al Estado de El Salvador a reparar a las víctimas de la masacre del Mozote ${ }^{26}$, a investigar los hechos, a sancionar a los culpables de entorpecer la investigación, a garantizar la no repetición de estos

24. Véase Corte Interamericana de Justicia. (El Mozote y lugares aledaños vs. El Salvador). (2012).

25. Id.

26. La sentencia establece las siguientes cantidades: (a) USD 35000 (treinta y cinco mil dólares de los Estados Unidos de América) a cada una de las víctimas de ejecución extrajudicial, señaladas en el Anexo "A" de esta sentencia; (b) UsD 20000 (veinte mil dólares de los Estados Unidos de América) a cada una de las víctimas sobrevivientes de las masacres, señaladas en el Anexo "B" de esta sentencia; y (c) USD 10000 (diez mil dólares de los Estados Unidos de América) a cada uno de los demás familiares de las víctimas ejecutadas, señaladas en el Anexo "C" de esta sentencia. Véase Corte Interamericana de Justicia, supra, nota 24. hechos y a pedir disculpas públicas, situación que efectivamente se llevó a cabo bajo el mando del presidente Mauricio Funes en el 2012. ${ }^{27}$

La crudeza del conflicto salvadoreño es un recordatorio de las difíciles condiciones que debe enfrentar una sociedad que se alza indefensa ante las acciones de los combatientes, quienes desgraciadamente no conocen, como es evidente, la distinción entre quienes participan del conflicto y quienes por disposiciones internacionales están protegidos. Aun hoy, varios lustros después, las heridas no cierran del todo, ya que, en casos como el del Mozote, no ha sido posible identificar a todos los que sucumbieron ante el poderío de las armas. El posconflicto de El Salvador aún, a pesar de haber contado con las mejores intenciones de un tribunal de la verdad y con leyes que buscaban el "perdón y el olvido", no escapa a los ojos de las reglas del derecho internacional que ve con malos ojos que exista una cortina de humo para ocultar los denuestos a quienes no estaban obligados a soportarlos. No obstante, dichas leyes de amnistía buscaban - sin justificar, claro está-, cerrar el capítulo de la violencia y empezar una sociedad con retos, realidades y situaciones que se alejan de la violencia generalizada de este infierno.

La inclusión posterior a la firma de los acuerdos de Chapultepec del FmLN en su calidad de partido político, surgió como una concesión obligada para aquellos que depusieron las armas y buscaban un proyecto político alejado de estas. Dicho partido, que no cambió su nombre con posterioridad a la dejación de las armas, se establece desde el 2009 como la primera fuerza electoral del El Salvador.

El conflicto de El Salvador muestra una cara diferente a la de Nicaragua en cuanto al manejo del posconflicto, pero con iguales consecuencias en lo social y en lo jurídico. En lo social persiste el problema de la apropiación de la tierra (el cual en las negociaciones de paz fue uno de los temas centrales); esto es, la posibilidad de ser dueño de un medio de subsistencia y de producción. De acuerdo con Vilas, ${ }^{28}$ en el proceso de transferencia de tierras a los exmiembros de las Fuerzas Militares de El Salvador y a excombatientes del FMLN, se les ha frenado su inclusión en este programa por falta de voluntad política, lo cual ha dejado

27. La Prensa Gráfica. 2012. Funes pide perdón por masacre El Mozote y anuncia medidas de reparación. LAPRENSAGRAFICA.COM. Disponible en http://www.laprensagrafica.com/el-salvador/politica/243467-funes-pide-perdon-por-masacre-el-mozote-y-anuncia-medidas-de-reparacion.html

28. Véase Carlos M. Vilas. Un balance de la ejecución de los acuerdos de paz en El Salvador. PAPers, Revista De Sociología 49. 1996. Pág. 82. 
por fuera de este ítem de negociación a alrededor de 30000 excombatientes.

La desproporción en la repartición de los ingresos en la década de los noventa, posterior a la firma de la paz era, a falta de una palabra más acertada, "descomunal", ya que el nivel de ingresos del $20 \%$ inferior de la población era del $4 \%$, y del $20 \%$ superior era del $49,5 \%$. Esto muestra una brecha inmensa en el nivel de ingresos, y evidencia la falta de programas de fomento de empleo para el posconflicto salvadoreño, país que mostraba un nivel de desempleo grande en el ámbito rural y un bajo nivel de ocupación de la mano de obra urbana. Esto, a todas luces, es un ambiente poco propicio para un país con grandes rupturas del tejido social por un prolongado conflicto. ${ }^{29}$

La Comisión de la Verdad para El Salvador, en su documento titulado Nunca más, muestra una radiografía de lo ocurrido, así como las graves violaciones al DIH que se cometieron. En concreto, y no por falta de importancia de las demás, en el caso de la masacre del Mozote y los lugares aledaños, tal y como arriba se describe, resulta evidente la falta de persecución del Estado a estos crímenes, amparado en las leyes de amnistía. Esto, frente a los estándares de justicia internacional, es una grave situación de impunidad que al sol de hoy sigue latente, ya que el Estado aduce que no existen registros de la composición del grupo que perpetró este execrable acto.

\section{El POSCONFLICTO Y LOS MECANISMOS NO PENALES EN Guatemala}

El conflicto interno que vivió Guatemala durante más de 30 años (1960-1996) fue uno de lo más enrevesados y difíciles de este hemisferio. Las diferencias culturales que tiene el pueblo guatemalteco entre las "clases" existentes, profundizó la gravedad de lo ocurrido. Es necesario - a fin de entenderlo- adentrarse en la historia de Guatemala desde un poco antes del inicio de las hostilidades entre el Estado y las guerrillas. Es un conflicto financiado por bandos antagónicos en cuanto a ideología se trata, esto es, por el bando estatal, Estados Unidos en su constante empuje hegemónico por mantener a una América libre de "comunismo", por el otro, la antigua Unión Soviética en busca su expansión socialista hacia América con Cuba como punto de referencia.

29. Id.
La hegemonía de los Estados Unidos fue muy fuerte siempre en Guatemala, por medio de la United Fruit Company (UFC). Siempre hubo un evidente favoritismo del Estado en perjuicio de las necesidades del pueblo, pues estas empresas no pagaban impuestos y, además, con la anuencia del Estado, hacían uso de las mejores y más fértiles tierras para la explotación de su razón social. En los días previos al derrocamiento del presidente electo democráticamente, Jacobo Arbenz, a manos de la cia - tal y como lo expone GarcíaFerreira $^{30}$-, después de un Gobierno que buscó una reforma agraria (naturalmente con la oposición de la UFC), se encontró en la penosa necesidad de entregar el mando a otro militar, a refugiarse en la Embajada mexicana y, finalmente, radicarse en ese país bajo la figura del asilo.

Los años posteriores para Guatemala serían turbulentos e inestables en el ámbito político. Pasarían varias juntas militares hasta la elección del presidente Manuel Idígoras-Fuentes, de radical corte anticomunista, quien fue depuesto (sin novedad en ese sentido) por Enrique Peralta-Azurdia (de facto). La inestabilidad política de Guatemala llevó de nuevo a este país a un gobierno de las juntas militares. Años después de Peral-Azurdia, a las manos del General Efraín RíosMontt (1982-1986) y, finalmente, y como principio de la era democrática moderna, la elección de Marco Vinicio Cerezo.

Sin embargo, visto el contexto histórico, es necesario abordar en este prolongado conflicto - desde la óptica dada-, la propuesta de los acuerdos de Esquipulas I y II, iniciativa del entonces presidente Marco Vinicio Cerezo, quien se podría decir es el precursor de las diferentes negociaciones de paz que, como podrá observarse, ocurrieron en diferentes momentos en los países en conflicto. Curiosamente, la paz para Guatemala se daría casi al final de la década de los noventa, más concretamente, de 1991 a 1996.

Los acuerdos de Esquipulas trajeron a Guatemala la creación de la CNR o Comisión Nacional de Reconciliación, al igual que en Nicaragua, en obediencia al numeral 1, Literal c, del mencionado Acuerdo del 11 de septiembre de 1987. Como primer momento de actuación, se encuentran los acuerdos de Oslo, celebrados en Noruega en marzo de 1990, pactándose el inicio de las conversaciones entre el Gobierno de Guatemala y las guerrilla Unidad Revolucionaria Nacional de Guatemala (URNG), un

30. Véase Roberto García-Ferreira. La CIA y el exilio de Jacobo Árbenz. Perfiles Latinoamericanos 28. Julio-diciembre. 2006. Disponible en http://www.redalyc. org/pdf/115/11502803.pdf el día 29 de Septiembre de 2015. 
Tabla 1. Gobiernos de Guatemala desde 1898 hasta 1986

\begin{tabular}{|c|c|c|}
\hline Años & Gobernantes & Carácter \\
\hline 1898-1920 & $\begin{array}{l}\text { General Manuel Estrada } \\
\text { Cabrera }\end{array}$ & Dictadura \\
\hline 1920-1931 & $\begin{array}{l}\text { General José María Orellana y } \\
\text { otros gobiernos muy breves }\end{array}$ & De facto \\
\hline 1931-1944 & General Jorge Ubico & Dictadura \\
\hline 1944-1945 & Junta cívico-militar & De facto \\
\hline 1945-1951 & Juan José Arévalo Bermejo & $\begin{array}{l}\text { Constitucional- } \\
\text { electo }\end{array}$ \\
\hline 1951-1954 & $\begin{array}{l}\text { Coronel Jacobo Arbenz } \\
\text { Guzmán }\end{array}$ & $\begin{array}{l}\text { Constitucional- } \\
\text { electo }\end{array}$ \\
\hline $1954-1957$ & Coronel Carlos Castillo Armas & De facto \\
\hline 1957-1958 & $\begin{array}{l}\text { Gobiernos generales muy } \\
\text { breves }\end{array}$ & De facto \\
\hline $1958-1963$ & $\begin{array}{l}\text { General Miguel Idígoras } \\
\text { Fuentes }\end{array}$ & Electo \\
\hline 1963-1966 & $\begin{array}{l}\text { Coronel Enrique Peralta } \\
\text { Azudia }\end{array}$ & De facto \\
\hline $1966-1970$ & Julio César Méndez Montenegro & Electo \\
\hline $1970-1974$ & General Carlos Arana Osorio & Electo \\
\hline 1974-1978 & General Kjell E. Laugerud & Electo \\
\hline 1978-1982 & General Romeo Lucas García & Electo \\
\hline $1982-1983$ & $\begin{array}{l}\text { General José Efraín Ríos } \\
\text { Montt }\end{array}$ & De facto \\
\hline 1983-1986 & General Óscar Mejía Víctores & De facto \\
\hline 1986 & Vinicio Cerezo Arévalo & $\begin{array}{l}\text { Constitucional- } \\
\text { electo }\end{array}$ \\
\hline
\end{tabular}

Fuente: Associació d'Amistat amb el Poble de Guatemala. GuateMALA A GRANDES TRAzos. (2005). Disponible en http://www.aapguatemala.org/05_brigades/ descarregues/dossier1_historia.pdf

histórico grupo que tuvo sus inicios en la década de los setenta, y en 1982 con la fusión de cuatro corrientes diferentes: Ejército Guerrillero de los Pobres (EGP), la Organización del Pueblo en Armas (ORPA), las Fuerzas Armadas Rebeldes (FAR), y el Partido Guatemalteco del Trabajo (PGT). De esta manera, se consolidó con el nombre de URNG. ${ }^{31}$

La paz para Guatemala fue, como en la mayoría de países donde ha existido un conflicto difícil, obtenida con sufrimiento. El vivo ejemplo de este sufrimiento es la masacre de Las Dos Erres, caso ocurrido en circunstancias muy similares a lo ocurrido con el

31. Véase Associació d'Amistat amb el Poble de Guatemala. Guatemala a grandes trazos. (2005). Disponible en http:// www.aapguatemala.org/05_brigades/ descarregues/ dossier1_historia.pdf
Mozote en El Salvador. Un grupo de Kaibiles (grupo militar especializado), entró a la población de Las Dos Erres y cercó el pueblo en busca de armamento y guerrilleros. Al otro día, después del desayuno y sin haber encontrado lo que fueron a buscar, paso a "vacunar" a la población, tal y como lo relata el fallo sobre la materia de la Corte Interamericana. ${ }^{32}$

Los acuerdos de Esquipulas iI que, para El Salvador y Nicaragua trajeron prontos acuerdos de paz, no lo hicieron tanto así para Guatemala, donde el conflicto se prolongó un tiempo más. Concretamente hasta 1996, cuando se firmaron los acuerdos para la paz firme y duradera, antecedidos por la firma de documentos de gran importancia como los acuerdos de Oslo de diciembre de 1996, en los que se discutió y aprobó el cese al fuego, la separación de fuerzas, la desmovilización y su debida verificación. El mencionado documento trae consigo todo un despliegue de operaciones que se realizaron para la seguridad de los hechos, la entrega de armas y el material bélico, lo que llevó, por supuesto, a la efectiva desmovilización de las fuerzas de la URNG. ${ }^{33}$

La firma de los acuerdos para la paz duradera se llevó a cabo el 29 de diciembre de 1996, momento en que se realiza una clara enunciación de los conceptos que rigieron esa firma de paz, tales como los derechos de los desplazados, de las etnias, el nuevo rol del ejército y la inclusión de la URNG a la unidad nacional, ya no como un grupo armado, sino como un grupo político con plenas dignidades y una inclusión sin ningún tipo de discriminación, lo cual resulta necesario y fundamental para la obtención de la paz, tal y como lo enuncia el título del documento "Firme y duradera".

El documento Guatemala: memoria del silencio presenta la memoria histórica de lo ocurrido en los años del conflicto. Este fue fruto de los acuerdos de Oslo de 1994, en los que, con la creación de la Comisión para el Esclarecimiento Histórico ( $\mathrm{CEH})$, se dieron a la titánica tarea de "mirar en el espejo del pasado" lo ocurrido en los 36 años de conflicto que vivió este

32. Véase Corte Interamericana de Justicia. (Caso de la Masacre de Las Dos Erres vs. Guatemala). (2009).

33. No solo existen los puntos mencionados en este acápite, existe una gran variedad de temas que fueron tratados en diferentes momentos de las negociaciones de paz en Guatemala, y que por su extensión y especialidad, se alejan un poco del tema que se trata: Acuerdo Calendario Negociaciones, Acuerdo Cese al Fuego, Acuerdo de Cronograma, Acuerdo Establecimiento CEH, Acuerdo Fortalecimiento Poder Civil, Acuerdo Global sobre Derechos Humanos, Acuerdo Incorporación URNG, Acuerdo Marco Reanudación, Acuerdo para el Reasentamiento, Acuerdo Político Democratización, Acuerdo Pueblos Indígenas, Acuerdo Reformas Constitucionales y Acuerdo Socioeconómico. 
país. Ahora, si bien es traumático aceptar lo que se vivió, resulta enaltecedor saber que se superaría ese terrible momento y que el derecho a saber la verdad del pueblo era mucho más grande. Existe dentro del contenido un extraordinario trabajo compilatorio de normas de amnistía - o, para efectos de este estudio, mecanismos no penales-, utilizados por los gobiernos desde 1950. Quizás se remonte un poco más atrás de lo que se planteó como el tiempo del conflicto como tal (1960-1996), mas se tuvo en cuenta el momento a partir del cual surge como tal la revolución, que es a partir de la creación de movimientos rebeldes como el MR-13, en adelante.

Bajo el mando del General Miguel YdígorasFuentes, se expidió el Decreto 1417 de 1960, en el cual se concede una amnistía para los autores y encubridores de delitos políticos y comunes conexos cometidos antes y con ocasión del 13 de noviembre de 1960, con excepción, entre otros, de los autores, cómplices y encubridores del asesinato del coronel Francisco Javier Arana y el coronel Carlos CastilloArma. Es necesario ahondar un poco en este aspecto, ya que se produjeron arrestos de elementos asociados al Partido Guatemalteco del Trabajo (PGT), al Partido Revolucionario (PR), y al Partido de Unidad Revolucionaria (PUR), a manera de retaliación, en esta intentona de golpe de Estado por parte de elementos militares, la cual fracasó debido al abrumador poder aéreo que tenía disponible el gobierno - ya que, en ese momento, se estaban entrenando en tierras guatemaltecas elementos anticastristas, los cuales avasallaron con su poder aéreo a los rebeldes-.

Se encuentra también el Decreto N. ${ }^{\circ} 1538$ del 28 de junio de 1962, por el cual se otorga amnistía a los participantes de los sucesos del 13 de noviembre de 1960, con excepción de: (a) los cabecillas, (b) los autores de asesinato y (c) quienes con posterioridad hayan cometido robos, asesinatos, violaciones o hayan atacado patrullas o unidades del Ejército, situación que propone la amnistía pero con la limitante de aquellos que hubieran atacado patrullas del ejército, cometido homicidios o cometido hurtos o violaciones con ocasión de los hechos de aquel día.

El Decreto N. ${ }^{\circ} 1605$ de Mayo de 1966 concede amnistía por delitos políticos y comunes conexos, cometidos desde el 1 de noviembre de 1960, hasta el 26 de julio de 1966, lo cual aparece como la primera amnistía amplia para los delitos ocurridos en un lapso de seis años de iniciado el conflicto. Vale la pena resaltar que se hace la aclaración de que se incluyen en este aspecto los delitos comunes conexos con los delitos políticos, lo cual es una ventana bastante amplia para la inclusión de cuestiones que en otros momentos podrían parecer inexcusables. Con esto, quedarían cubiertos por esta amnistía cuestiones tales como homicidios y porte ilegal de armas, siempre y cuando aparezcan como conexos a los delitos políticos.

Asimismo, este decreto concede amnistía por delitos políticos y comunes conexos, cometidos desde el 1 de noviembre de 1960 hasta el 26 de julio de 1966, y comprende a los autores cómplices y encubridores. A fin de que esta amnistía sea aplicable en los casos de tenencia ilícita de armas y plagio de personas, las primeras deberán ser entregadas, y las segundas puestas en libertad, por primera vez condicionando una amnistía a la entrega de armas y puesta en libertad de secuestrados.

En el poder, el general Efraín Ríos-Montt, por medio de golpe de Estado, en 1982, se dio una curiosa apertura a la participación en política de los grupos rebeldes. Se promulgaron leyes de amnistía para facilitar este proceso en un documento de cuatro artículos, tales como el Decreto 033 de 1982, por el cual se concede amnistía por delitos políticos, comunes y conexos, en los cuales hubiesen participado - como autores o cómplices-, las personas que individual o colectivamente formen o hayan formado parte de las facciones subversivas que han venido actuando de forma violenta en contra del orden jurídico político de la nación, o hubiesen cometido el delito de encubrimiento en relación con tales actos. Para que la presente amnistía surta efecto, las personas que se encuentran favorecidas por esta deberán presentarse voluntariamente y dentro de un plazo de 30 días ante la autoridad militar más cercana, y manifiesten bajo juramento legal que no participarán en lo sucesivo en actividades subversivas. Cuando se trate de secuestro de personas, los que deseen acogerse a la amnistía deberán entregar sano y salvo al plagiado.

En el Gobierno democrático del presidente Marco Vinicio Cerezo, se expide el Decreto 08 de 1986, por el cual se concede amnistía general a toda persona responsable o sindicada de haber cometido delitos políticos y comunes conexos durante el periodo que abarca desde el 23 de marzo de 1982, hasta el 14 de enero de 1986. No podrá entablarse ni seguirse acción penal de ninguna especie contra autores y cómplices de tales delitos, ni contra quienes hubieren cometido el delito de encubrimiento en relación con los referidos hechos. Así, aparece esta norma con el fin de cubrir el periodo de entrada al poder del general Ríos-Montt, su salida y el paso a la democracia que exigió otro golpe de Estado, esta vez 
a manos del general Mejía-Victores, quien fuera su ministro de Defensa.

Una vez cerrando el ciclo de las negociaciones con la guerrilla de las URNG en 1996, el gobierno expide el Decreto 146 de 1996, el cual, es evidente, resulta un documento mucho más aterrizado a las realidades de un posconflicto de finales del siglo $\mathrm{xx}$, esto es, un conflicto en el que los tratados internacionales no se pueden ignorar, y en el que los delitos de lesa humanidad no pueden ser sobreseídos, dada su condición de crímenes contra la humanidad. La ley de amnistía en comento trae consigo un perdón de todos los delitos comunes conexos con los delitos de naturaleza política, los cuales, en el Código Penal de Guatemala son: traición, ultraje a símbolos patrios de nación extranjera, rebelión y sedición, entre otros. Es importante destacar que aquellos delitos que, por disposición interna o compromiso internacional, no pudieran hacer parte del Decreto 146 de 1996, deben ser procesados de acuerdo con el Código de Procedimiento Penal de Guatemala (Decreto 51-92). Otros delitos que no podrían ser parte de la amnistía son los delitos de genocidio, tortura y desaparición forzada, por expreso mandamiento del artículo 8 de la ley de amnistía.

Se encomienda a la Comisión para el Esclarecimiento Histórico una tarea de titánicas proporciones, pero que sin la cual no habría sido posible poner de manifiesto todos aquellos hechos ocurridos en el trasegar del conflicto, de manera que estarían destinados al olvido, lo cual resultaría desastroso, y más con el fundamental derecho de las víctimas a conocer la verdad y tener un acceso debido a la justicia.

Con las recomendaciones hechas por el $\mathrm{CEH}$, se atenderá, de manera humanitaria, a las víctimas del conflicto en razón a su necesidad, lo cual resulta atinado, pero con cautela, ya que el criterio de priorización para la atención a aquellos que requieren de atención debe ser, por lo menos, moderadamente estricto.

El posconflicto en Guatemala estuvo bien intencionado, y en la documentación revisada existen muchos elementos que permitirían inferir cómo el logro de la paz para este país fue muy grande, pero no siempre el paso a la finalización de la guerra ocurre de forma suave y sin eventos adversos. Curar las heridas de un conflicto tan prolongado y lleno de violaciones a los derechos humanos, junto con el "genocidio" del pueblo Ixil de Guatemala a manos de agentes del Estado - lo cual resulta como uno de los ítems inconclusos para el posconflicto, tal y como lo propone la Federación Internacional de Derechos
Humanos (FIDH). ${ }^{34}$ Según la FIDH, hubo una sentencia en contra del general Efraín Ríos-Montt condenándolo a 80 años por el delito de genocidio, lo cual resulta paradigmático, dado que es el primer fallo en contra de un exmandatario latinoamericano por este delito. El general Ríos-Montt, no obstante la abultada condena que recibió, resultó favorecido por un recurso de su equipo jurídico presentado al Tribunal Constitucional de Guatemala, en el que en una votación dividida (tres a favor y dos en contra) se ordena retrotraer el proceso a una etapa previa, dejando así sin efectos la sentencia dictada. ${ }^{35}$

\section{Marco Comparativo de las ETAPAS}

\section{DEL POSCONFLICTO CENTROAMERICANO}

\section{Y SUS ENSEÑANZAS PARA COLOMBIA}

Resulta importante, a partir de las enseñanzas que dejan conflictos asimétricos tan similares al de Colombia, extraer aquellas experiencias que necesariamente se deben considerar en procura de un posconflicto relativamente exitoso, y porqué se refieren a él de manera relativa, en razón a que nunca será fácil abordar la titánica labor de engranar una etapa de finalización de conflicto con las necesarias reivindicaciones y exigencias que trae consigo. No obstante, debe procederse a ello sin titubeos, ya que de ello depende en muchos aspectos el futuro de un país.

Nicaragua es un referente de tipo negativo para la experiencia colombiana, ya que lo ocurrido en este país, si bien dista en su concepción ideológica de lo ocurrido en Colombia (en Nicaragua ocurrió al contrario el conflicto: recuérdese que el Gobierno estaba, en aquel entonces, liderado por el FsLn que había, por la vía de las armas, llegado al poder en 1979, y era la Contra, el grupo patrocinado por los Estados Unidos, de "derecha", el que hacía la oposición armada al Estado).

A pesar de estas diferencias, es necesario tener en cuenta que la paz, tal como ocurrió en Nicaragua, ofrece un ejemplo de qué no se debe hacer para enfrentar un posconflicto, aun a pesar del éxito que ofreció en ese caso particular. La finalización del conflicto se dio de forma no negociada, ni escalonada, ni teniendo en cuenta derechos ni memoria histórica

\footnotetext{
34. Véase Federación Internacional de Derechos Humanos-FIDH Genocidio en Guatemala: Ríos Montt Culpable. (2013). Disponible en https://www.fidh.org/IMG/pdf/ informe_guatemala613esp2013.pdf

35. Id. Págs. 26-27.
} 
de la población, lo cual es a todas luces lo que se considera una paz de características amnésicas en la cual, sin mediar ningún tipo de consideración, se procede a firmar una paz con un grupo antagónico sin tener en cuenta los derechos a ser reparados o a ser visibilizados que tienen aquellos que padecieron los horrores de la guerra, además de los estándares de justicia mínimos que debe tener en cuenta un proceso de paz, ya que las amnistías totales están proscritas a la luz de la normatividad internacional. ${ }^{36}$

Una paz que no tenga en cuenta unos mínimos estándares no puede considerarse una paz completa. Así lo recuerda el postulado de Ohlin, ${ }^{37}$ en el que se plantea la norma anti o contra impunidad, la cual propone que aquellos que no sean de alguna forma castigados $\mathrm{o}$, en estos casos, se vean moralmente obligados a decir la verdad y pedir perdón por sus actos, eventualmente terminaran por cometer de nuevo aquellas malas conductas. Asimismo, aquellos que no hayan encontrado algún tipo de justicia en su momento, en el futuro se verán envalentonados a la hora de cometer algún tipo de conducta reprochable, ya que saben que la justicia es inoperante.

Colombia ha cumplido con los estándares internacionales en cuanto a esta situación, al entender que una amnistía, de forma absoluta, está por fuera de la cuestión. Ahora bien, de acuerdo con el protocolo adicional II, artículo 6.5, se establece que podrá, al finalizar las hostilidades, conceder la amnistía más amplia posible, situación que se acompasa con la normativa internacional y ha permitido, de forma diversa, aplicar medidas restrictivas de la libertad a los actores del conflicto y la aplicación de sanciones con tiempo especial. ${ }^{38}$

Las experiencias de paz en El Salvador y Guatemala ofrecen un panorama mucho más cercano a lo que debe ser una paz integral, con las obvias limitaciones que suponen estos procesos. Aparte de los consabidos mecanismos no penales, es decir, amnistías a los actores del conflicto - tal y como se explicó-, pero con dos elementos de fundamental importancia que Colombia, de forma sabia, adoptó en sus negociaciones de paz con las FARC. Estos son las memorias históricas que en ambos países centroamericanos se produjeron (Guatemala "Memoria del Silencio", y para el Salvador "Nunca más"), que ofrecen en ambos casos un recuento histórico de aquellos

\footnotetext{
36. Véase Kai Ambos, Ezequiel Malarino y Gisela Elsner. Justicia De transición. Informes de América Latina, Alemania, ItALIA Y EsPaña. Konrad-AdenauerStiftung. (2009).

37. Véase Jens Ohlin, supra, nota 23.

38. Véase Acuerdos para la paz estable y duradera. (2016).
}

casos que por su crudeza e impacto permiten a aquellos que los leen entender las verdaderas dimensiones de conflictos tan dilatados y tan enconados como los vividos en estos países.

La lección que ofrecen estos documentos son netamente de visibilización de víctimas, ya que son ellos los rostros ocultos y a veces ignorados de conflictos armados, así como la memoria histórica de aquellos hechos que jamás deben ser olvidados, ya que contienen el origen y las causas del conflicto y, en consecuencia, son garantía de no repetición; es decir, con la memoria de estos difíciles momentos se puede evitar que vuelvan a ocurrir en el futuro, por medio de un recuento de hechos que no puede un Estado permitir que vuelvan a suceder. Naturalmente, tienen un fin pedagógico estas memorias, pues enseñarán a las generaciones venideras - lo cual es absolutamente deseable desde la enseñanza básica-, que en sus países se vivieron conflictos de estas magnitudes, y cómo en sus manos está evitar que vuelvan a ocurrir.

En los acuerdos de paz del Gobierno de Colombia con las FARC se encuentra, en el punto 5.1.1.1, cómo la Comisión para el esclarecimiento de la verdad, la convivencia y no repetición, tendrá como fin primordial esclarecer y dar a conocer lo ocurrido en el conflicto $y$, con base en ello, evitar que vuelva a ocurrir alguna vez algo así. Esto se acompasa con las enseñanzas que puede ofrecer Centroamérica, y hace que el proceso de paz en Colombia sea uno que ofrece garantías y el cual, finalmente, se ha logrado con gran expectativa la entrega efectiva de las armas, las cuales se encuentran en poder de las Naciones Unidas.

\section{ConClusiones}

Existe un verdadero espacio de aprendizaje para Colombia, proporcionado por los países estudiados en este artículo. Sus prolongados y difíciles conflictos con actores armados de muy similar naturaleza a los colombianos, provee lecciones de aprendizaje imposibles de ignorar, ya que cada una de ellas fue especial a su manera; ignorarlas es, en palabras de Nicolás de Avellaneda, un error de aprendizaje, porque quien no conoce la historia está condenada a revivirla.

Guatemala ofrece un ejemplo muy valioso de paz, naturalmente accidentada, pero valiosa en dos sentidos concretos. Su comisión para el esclarecimiento de la verdad es un ejemplo para Colombia, ya que la inmensa tarea de esclarecer los hechos ocurridos será en extremo difícil, y más si se tienen en cuenta los decenios de duración de este conflicto. 
Es también un ejemplo la utilización de mecanismos como amnistías para los excombatientes.

Nicaragua, al contrario de Guatemala, ofrece un ejemplo, pero en sentido negativo, es decir, un ejemplo de qué no se debe hacer. La paz en Nicaragua ofreció un panorama especial en cuanto a su finalización, ya que no hubo un esclarecimiento de las causas del conflicto mismo, de su desarrollo o de los responsables de las atrocidades cometidas por bando y bando, lo que se colige como una paz de tipo amnésico, la cual debe erradicarse.

Esta no es la primera experiencia de paz en Colombia. Recuérdese la guerrilla de los llanos de Guadalupe Salcedo, el EPL, M-19 y Quintín lame. Esto provee a este país también de una experiencia única y muy valiosa para enfrentar la paz en la actualidad, pues la historia provee experiencias y antecedentes que deben ser tenidos en cuenta, ya que cada proceso es único en su desarrollo.

Aun cuando Centroamérica y Colombia compartan similitudes, cada uno de los procesos de paz es diferente, y cada país debe ser analizado con juicio antes de emprenderse un proceso de negociación, ya que basarse enteramente en un modelo extranjero es un error, ya que su trasplante puede resultar inviable.

\section{REFERENCIAS}

Acuerdo de Esquipulas, I. I. Procedimiento para estaBLECER LA PAZ FIRME Y DURADERA EN CENTROAMÉRICA. Ciudad de Guatemala. (1987).

Alto Comisionado para la Paz (2016). Acuerdo final para la terminación del conflicto y la construcción de una paz estable y duradera. Disponible en la página http://www.altocomisionadoparalapaz.gov.co/procesos-y-conversaciones/Documentos\%20compartidos/24-11-2016NuevoAcuerdoFinal.pdf

Associació d'Amistat amb el Poble de Guatemala. GuateMALA A GRANDES TRAzos. Disponible en http://www. aapguatemala.org/05_brigades/descarre gues/dossier1_historia.pdf

Camilo Devia-Garzón, Dina Ortega y Marcela Magallanes. (2014). ViolenCia LUEgo de LA PAZ: ESCENARIOS DE posconflicto en Centroamérica. Universidad Militar Nueva Granada. Disponible en http://revista. urepublicana.edu.co/wp-content/uploads/2015/02/ Violencia-luego-de-la-paz-escenarios-de-posconflicto-en-Centro-.pdf

Carlos M. Vilas. Un balance de la ejecución de los acuerdos de paz en El Salvador. Papers, Revista de Sociología 49. 1996. Pág. 82.
Colombia.co. ¿Por qué se dice que Colombia tiene la democracia más antigua de América Latina? Colombia. co. Disponible en http://www.colombia.co/esta-es-colombia/historia/por-que-se-dice-que-colombia-tiene-la-democracia-mas-antigua-de-america-latina/

Comisión de la Verdad para El Salvador. De la locura A LA ESPERANZA. Naciones Unidas. (1993).

Corte Interamericana de Justicia. (Caso de la Masacre de Las Dos Erres vs. Guatemala). (2009).

Corte Interamericana de Justicia. (El Mozote y lugares aledaños vs. El Salvador). (2012).

Daniel Matul y Alonso Ramírez. El proceso de paz en Centroamérica. Agendas pendientes y nuevos focos de conflictividad: Los casos de Guatemala y Nicaragua. Pensamiento Propio 29. Págs. 91-124. Disponible en http://www.cries.org/29.pdf

Decreto-Ley N. ${ }^{\circ}$ 47-91 [Presidencia de la República de Nicaragua]. Gaceta N. ${ }^{\circ} 246$ de 1991.

Ejército,D.N.EJÉrCITOdENICARAGUA3 3 AÑosDEVIDAINSTITUCIONAL:(1979-2009). Ejército de Nicaragua. (2009).

El País. El asesinato de Anaya pone en peligro el plan de paz en El Salvador. EL PAís.com. Octubre 28 de 1987. Disponible en http://elpais.com/diario/1987/10/28/internacional/562374016_850215.html

Federación Internacional de Derechos Humanos-FIDH. GEnocidio En Guatemala: Ríos Montt Culpable. (2013). Disponible en https://www.fidh.org/IMG/pdf/ informe_guatemala613esp2013.pdf

La Prensa Gráfica. 2012. Funes pide perdón por masacre El Mozote y anuncia medidas de reparación. LA Prensa Gráfica. 2012. Disponible en http://www. laprensagrafica.com/el-salvador/politica/243467-funes-pide-perdon-por-masacre-el-mozote-y-anuncia-medidas-de-reparacion.html

Ley N. ${ }^{\circ} 81$ de 13 de marzo de 1990 [Asamblea Nacional de la República de Nicaragua]. Gaceta N. ${ }^{\circ} 53$ de 15 de marzo de 1990.

Miguel Ángel Bastenier. Violeta Chamorro: "Aquí mando yo". EL PAís.com. Marzo 11 de 1990). Disponible http:// elpais.com/diario/1990/03/11/internacional/6371100 05_850215.html

Historiaybiografias.com. La dictadura de los Somoza en Nicaragua Gobierno Autoritario de Somoza. HistoRiaybiografias.com. 2016. Disponible en http://historiaybiografias.com/somoza/

Ignacio Martín-Baro. La guerra civil en El Salvador. Universidad Centroamericana José Simeón Cañas. (1981). Disponible en http://www.uca.edu.sv/coleccion-digital-IMB/articulo/la-guerra-civil-en-el-salvador/ 
Jens Ohlin. Justice After War. Cornell University. (2014). Disponible en http://papers.ssrn.com/sol3/papers. cfm?abstract_id $=2531963$

Kai Ambos, Ezequiel Malarino y Gisela Elsner. Justicia DE transición. Informes de América latina, Alemania, Italia y España. Konrad-AdenauerStiftung. (2009).
Roberto García-Ferreira. La CIA y el exilio de Jacobo Árbenz. Perfiles Latinoamericanos 28. Julio-diciembre. 2006. Disponible en http://www.redalyc.org/ pdf/115/11502803.pdf

V. García Pinzón. Reformas al sector seguridad en contextos de post-conflicto armado: experiencias en Centroamérica y consideraciones sobre el caso colombiano. Ponencia presentada en Conferencia Flacso-ISA: "Poderes Regionales y Globales en un Mundo Cambiante”, Buenos Aires, 2014. 